\title{
ON THE HYERS-ULAM-RASSIAS STABILITY OF A $n$-DIMENSIONAL QUADRATIC FUNCTIONAL EQUATION
}

\author{
Dong SEung Kang AND HaHng-Yun CHU
}

Abstract. Let $n \geqslant 2$ be an integer. In this paper, we investigate the generalized Hyers-UlamRassias stability of a $n$-dimensional quadratic functional equation on Banach spaces and Banach modules over a Banach algebra;

$$
(4-n) f\left(\sum_{j=1}^{n} x_{j}\right)+\sum_{i=1}^{n} f\left(\sum_{j=1}^{n} \theta(i, j) x_{j}\right)=4 \sum_{i=1}^{n} f\left(x_{i}\right),
$$

where the function $\theta$ is defined by $\theta(i, j)=\left\{\begin{array}{ll}1 & \text { if } i \neq j \\ -1 & \text { if } i=j\end{array}\right.$.

Mathematics subject classification (2000): 39B52.

Key words and phrases: quadratic mapping, functional equation, Hyers-Ulam-Rassias stability.

\section{REFERENCES}

[1] J. H. BAE, W. G. PARK, On the generalized Hyer-Ulam-Rassias in Banach modules over C* - algebra, J. Math. Anal. Appl., 294, (2004), 196-205.

[2] P. W. CholewA, Remarks on the stability of functional equations, Aequationes. Math., 27, (1984), 76-86.

[3] S. CZERWIK, On the stability of the quadratic mapping in normed spaces, Abh. Math. Sem. Univ. Hamburg, 62, (1992), 59-64.

[4] G. L. FORTI, Hyer-Ulam stabilty of functional equations in several variables, Aequationes Math., 50, (1995), 143-190.

[5] G. L. FORTI, Comments on the core of the direct method for proving Hyer-Ulam stabilty of functional equations, J. Math. Anal. Appl., 295, (2004), 127-133.

[6] P. GǍVRUTA, A generalization of the Hyers-Ulam-Rassias stability of approximatelyadditive mappings, J. Math. Anal. Appl., 184, (1994), 431-436.

[7] D. H. HyERS, On the stability of the linear equation, Proc. Nat. Acad. Sci. U.S.A., 27, (1941), 222-224.

[8] C. S. LIN, Sesquilinear and quadratic forms on modules over *-algebra, Publ. Inst. Math., 51, (1992), 81-86.

[9] C. G. PARK, Generalized quadaratic mapping in several variables, Nonlinear Anal. Theor. Method. Appl., 57, (2004), 713-722.

[10] C. G. PARK, On the Hyer-Ulam-Rassias stabilty of generalized quadratic mappings in Banach modules, J. Math. Anal. Appl., 291, (2004), 214-223.

[11] TH. M. RAssiAs, On the stability of the linear mapping in Banach spaces, Proc. Amer. Math. Soc., 72, (1978), 297-300.

[12] TH. M. RASSIAS, On the stability of functional equations in Banach spaces, J. Math. Anal. Appl., 251, (2000), 264-284.

[13] TH. M. RASSIAS, P. ŠEMrL, On the Hyers-Ulam stability of linear mappings, J. Math. Anal. Appl., 173, (1993), 325-338. 
[14] TH. M. RASSIAS, K. ShiBATA, Variational problem of some quadratic functions in complex analysis, J. Math. Anal. Appl., 228, (1998), 234-253.

[15] TH. M. RASSIAS, On the stability of functional equations and a problem of Ulam, Acta Appl. Math., 62, (2000), 23-130.

[16] F. SKOF, Proprietà locali e approssimazione di operatori, Rend. Semin. Mat. Fis. Milano, 53, (1983), 113-129.

[17] S. M. Ulam, Problems in Morden Mathematics, Wiley, New York (1960). 